\title{
Overexpression of SENP1 reduces the stemness capacity of osteosarcoma stem cells and increases their sensitivity to HSVtk/GCV
}

\author{
FENGTING LIU ${ }^{1}$, LILI LI ${ }^{1}$, YANXIA LI ${ }^{2}$, XIAOFANG MA ${ }^{3}$, XIYUN BIAN ${ }^{2}$, \\ XIAOZHI LIU ${ }^{2}$, GUOWEN WANG ${ }^{1 *}$ and DIANYING ZHANG ${ }^{3 *}$ \\ ${ }^{1}$ Department of Bone and Soft Tissue Tumors, Tianjin Medical University Cancer Institute and Hospital, Tianjin 300060; \\ ${ }^{2}$ Central Laboratory, The Fifth Central Hospital of Tianjin, Tianjin 300450; \\ ${ }^{3}$ Department of Trauma and Orthopedics, Peking University People's Hospital, Beijing 100044, P.R. China
}

Received January 19, 2018; Accepted July 17, 2018

DOI: 10.3892/ijo.2018.4537

\begin{abstract}
Osteosarcoma stem cells are able to escape treatment with conventional chemotherapeutic drugs, as the majority of them are in a quiescent state. Recent reports have suggested that small ubiquitin-like modifiers (SUMOs) serve important roles in the maintenance of cancer stem cell stemness. Therefore, a potential strategy to increase the effectiveness of chemotherapeutic agents is to interfere with SUMO modification of proteins associated with the maintenance of stemness in osteosarcoma stem cells. The present study revealed a significant decrease in the expression of SUMO1 specific peptidase 1 (SENP1) in osteosarcoma tissues and osteosarcoma cell lines, and SENP1 expression was much lower in osteosarcoma stem cells than in non-cancer stem cells. Further experiments indicated that the low levels of SENP1 were essential for maintenance of stemness in osteosarcoma stem cells. Overexpression of SENP1 resulted in a marked decrease in the maintenance of stemness, but only slightly induced apoptosis of osteosarcoma cells, which is crucial to reduce the side effects of drugs on normal precursor cells. Finally, SENP1 overexpression led
\end{abstract}

Correspondence to: Dr Guowen Wang, Department of Bone and Soft Tissue Tumors, Tianjin Medical University Cancer Institute and Hospital, 1 Huan-Hu-Xi Road, Ti-Yuan-Bei, Hexi, Tianjin 300060, P.R. China

E-mail:wgwhrb@163.com

Dr Dianying Zhang, Department of Trauma and Orthopedics, Peking University People's Hospital, 11 Xizhimen South Street, Beijing 100044, P.R. China

E-mail: zdy8016@163.com

*Contributed equally

Key words: small ubiquitin-like modifiers, osteosarcoma, cancer stem cells, herpes simplex virus 1 thymidine kinase, ganciclovir, chemotherapeutic drugs to a significant increase in the sensitivity of osteosarcoma stem cells to the herpes simplex virus 1 thymidine kinase gene in combination with ganciclovir in vitro and in vivo. In conclusion, the present study described a novel method to increase the sensitivity of osteosarcoma stem cells to chemotherapeutic drugs. Notably, this approach may significantly reduce the required dose of conventional chemotherapeutic drugs and reduce side effects.

\section{Introduction}

Osteosarcoma is among the most frequently occurring bone tumors in children and young adults, which is associated with a high rate of recurrence and early metastasis (1-3). Surgical resection combined with adjuvant chemotherapy is the leading treatment option for osteosarcoma $(4,5)$. However, the use of chemotherapeutic agents, including doxorubicin and cisplatin, is associated with a high risk of short-term and long-term effects, including cardiotoxicity and nephrotoxicity, thus resulting in undesirable outcomes $(6,7)$. One of the predominant factors that mediate failure of chemotherapy for the treatment of osteosarcoma is the existence of osteosarcoma stem cells (2,8-13). These cells are usually in a quiescent state $\left(G_{0}\right.$ phase), leading to the failure of conventional chemotherapeutic drugs to induce cell death (14-16). However, these quiescent cells can quickly reenter the cell cycle and begin rapid proliferation upon appropriate stimulation $(17,18)$.

It has previously been reported that some proteins, including proliferating cell nuclear antigen (PCNA), Oct4 and hypoxia-inducible factor- $1 \alpha(\mathrm{HIF}-1 \alpha)$, which maintain stemness of cancer stem cells, are regulated by the small ubiquitin-like modifier (SUMO) pathway (19-25). Due to the extensive and important role of SUMOs, direct SUMO gene silencing often leads to the death of various cell types, particularly precursor cells that participate in tissue repair, which may lead to serious side effects $(26,27)$.

SUMO1 specific peptidase 1 (SENP1) removes SUMO1, SUMO2 and SUMO3 from target proteins, and regulates their transcriptional activity (28). Notably, it is often involved in 
deSUMOylation of specific target proteins, which is beneficial for their recycling (29).

Previous studies have demonstrated that the herpes simplex virus thymidine kinase (HSVtk) gene and complementary treatment with ganciclovir (GCV) inhibit the growth of various types of tumor cells, including glioma, breast cancer, hepatocellular carcinoma, gastric cancer and bladder cancer (30-34). The expressed HSVtk enzyme and endogenous kinases phosphorylate GCV, which is converted into an active and abnormal triphosphate guanosine analog. Its subsequent insertion in elongating DNA by cellular DNA polymerases induces premature chain termination and apoptosis (35). Since the HSVtk-GCV system is one of the most efficient approaches to induce cell death of rapidly dividing cells (36), the present study used it as a chemotherapeutic drug. This study aimed to determine the effects of SENP1 on the deSUMOylation of four stemness-maintaining proteins, PCNA, Oct4, HIF-1 $\alpha$ and protein kinase $\mathrm{B}$ (Akt1), and its effects on the sensitivity of osteosarcoma stem cells to the HSVtk-GCV system.

The present study revealed that overexpression of SENP1 decreased the stemness of osteosarcoma stem cells, but only slightly affected cell migration and apoptosis. In addition, SENP1 overexpression significantly increased the sensitivity of osteosarcoma stem cells to HSVtk/GCV in vitro and in vivo. The present study provided novel insights into the treatment of osteosarcoma, particularly cancer stem cells that are not sensitive to conventional chemotherapeutic drugs. In addition, this potential treatment strategy may allow for a significant reduction in the dose of chemotherapeutic drugs and their associated side effects.

\section{Materials and methods}

Tissue specimens. A total of 18 fresh osteosarcoma tissue samples were collected between January 2016 and December 2016 from patients ( 7 female and 11 male patients; age range, $12-55$ years old) who had not undergone radiotherapy or chemotherapy prior to surgery at the Department of Bone and Soft Tissue Tumors, Tianjin Medical University Cancer Institute and Hospital (Tianjin, China). A senior pathologist completed the initial diagnosis of all frozen samples. The partial tissue samples were fixed in $10 \%$ neutral-buffered formalin (Bios Europe Ltd., Skelmersdale, UK) overnight at room temperature, were processed using a Tissue-Tek VIP automatic tissue processor (Sakura Finetek Europe B.V., Flemingweg, The Netherlands) with a standard 14-h protocol, and were embedded in paraffin wax (Tissue-Tek; Sakura Finetek Europe B.V.). Sections $(5 \mu \mathrm{m})$ were then cut from the embedded blocks, and the paraffin-embedded sections were re-examined by another pathologist to confirm the initial diagnosis. The present study was approved by the ethics committee of Tianjin Medical University Cancer Institute and Hospital, and written informed consent was obtained from all patients.

Cell lines and cell culture. Three osteosarcoma cell lines, 143B, MG-63 and U-2OS, and an osteoblast cell line hFOB1.19 were purchased from American Type Culture Collection (Manassas, VA, USA). All cells were maintained in Dulbecco's modified Eagle's medium (DMEM) supplemented with $10 \%$ fetal bovine serum (FBS) (both from Gibco; Thermo
Fisher Scientific, Inc., Waltham, MA, USA), 100 U/ml penicillin and $100 \mu \mathrm{g} / \mathrm{ml}$ streptomycin (both from Sigma-Aldrich; Merck KGaA, Darmstadt, Germany) at $37^{\circ} \mathrm{C}$ in an atmosphere containing $5 \% \mathrm{CO}_{2}$.

Cancer stem cell separation and culture. The 143B osteosarcoma cells were digested with $0.25 \%$ trypsin (Gibco; Thermo Fisher Scientific, Inc.) and were pipetted into a single-cell suspension. Cells were suspended in $100 \mu \mathrm{l}$ PBS, stained with Alexa Fluor ${ }^{\circledR}$ 488-labeled anti-cluster of differentiation CD133 antibody (0.5 $\mu \mathrm{g} / \mathrm{million}$ cells; cat. no. MAB 4310X; EMD Millipore, Billerica, MA, USA) for $30 \mathrm{~min}$ at $37^{\circ} \mathrm{C}$ in the dark and re-suspended with $1 \%$ paraformaldehyde $(600 \mu 1)$. Subsequently, CD133+ and CD133- cells were separated using flow cytometry, according to a previously described study (37). The CD133+ cells were cultured in DMEM/F12 medium containing B27 (both from Gibco; Thermo Fisher Scientific, Inc.), $20 \mathrm{ng} / \mathrm{ml}$ basic fibroblast growth factor (Miltenyi Biotec GmbH, Bergisch Gladbach, Germany) and $20 \mathrm{ng} / \mathrm{ml}$ epidermal growth factor (Provitro Biosciences, LLC, Mount Vernon, WA, USA), and were incubated at $37^{\circ} \mathrm{C}$ in an atmosphere containing $5 \% \mathrm{CO}_{2}$. To maintain osteosarcoma stem cells in states of quiescence, proliferation or differentiation, agarose gel matrix medium containing B27 (Gibco; Thermo Fisher Scientific, Inc.) and 0.025 or $3 \mathrm{~g}$ low melting point agarose (Nanjing Sunshine Biotechnology Co., Ltd., Nanjing, China), in combination with basic fibroblast growth factor (20 ng/ml; Miltenyi Biotec $\mathrm{GmbH}$ ) and epidermal growth factor (20 ng/ml; Provitro Biosciences, LLC) was used, according to a previously reported method (38). The dynamic morphology of cell clones was observed and captured under an inverted microscope (Olympus CKX41; Olympus Corporation, Tokyo, Japan).

Western blotting. Tissue or cell proteins were extracted using radioimmunoprecipitation assay (RIPA) extraction buffer (cat. no. R0010; Beijing Solarbio Science \& Technology Co., Ltd., Beijing, China) with one protease inhibitor (Roche Diagnostics, Basel, Switzerland) per $10 \mathrm{ml}$ RIPA, phenylmethylsulfonyl fluoride (1:100, cat. no. R0010) and N-ethylmaleimide (200 mM, cat. no. N8760) (both from Beijing Solarbio Science \& Technology Co., Ltd.). Bicinchoninic acid assay (cat. no. PC0020; Beijing Solarbio Science \& Technology Co., Ltd.) was used for protein quantification, after which, the proteins (30 $\mu \mathrm{g} / \mathrm{lane})$ were separated by $4-20 \%$ pre-cast protein gel electrophoresis (Bio-Rad Laboratories, Inc., Hercules, CA, USA). Following gel electrophoresis, proteins were transferred to polyvinylidene fluoride membranes (EMD Millipore), which were blocked with $5 \%$ skimmed milk and $0.1 \%$ Tris-buffered saline with $1 \mathrm{ml} / 1$ Tween-20 for $1 \mathrm{~h}$ at $37^{\circ} \mathrm{C}$. The membranes were then incubated with anti-SUMO1 (1:2,000, cat. no. ab133352), anti-SENP1 (1:5,000, cat. no. ab108981), anti-PCNA (1:1,000, cat. no. ab18197), anti-Oct4 (1:1,000, cat. no. ab18976), anti-Akt1 (1:5,000, cat. no. ab235958), anti-HIF-1 $\alpha$ (1:1,000, cat. no. ab82832), anti-matrix metalloproteinase (MMP)2 (1:1,000, cat. no. ab37150), anti-MMP9 (1:1,000, cat. no. ab38898), anti-caspase-3 (1:500, cat. no. ab13847) or anti- $\beta$-actin $(1: 1,000$, cat. no. ab8227) (all from Abcam, Shanghai, China) antibodies overnight at $4^{\circ} \mathrm{C}$. The membranes were then incubated for $1 \mathrm{~h}$ at room temperature with horseradish peroxidase-conjugated 
chicken anti-rabbit immunoglobulin $\mathrm{G}(\mathrm{IgG})$ secondary antibodies (1:2,000, cat. no. sc-516087; Santa Cruz Biotechnology, Inc., Dallas, TX, USA). Labeled proteins were detected using a Super Signal protein detection kit (Pierce; Thermo Fisher Scientific, Inc.). Changes in the levels of proteins were evaluated using ImageJ analysis software (Java 1.6.0-20 32-bit; National Institutes of Health, Bethesda, MD, USA).

Gene transduction. Dominant-negative mutant SUMO1 [small interfering RNA (siR)-neg] plasmids (5'-GATCCGAATTGC CACAACAGGGTCGTGTTCAAGAGAATCACATCTTCTT CCTCCATTCTTTTTTG-3') or the same DNA fragment carrying siR-SUMO1 (5'-GATCCGCCTTCATATTACCCTCT CCTTTCAAGAGAAGGAGAGGGTAATATGAAGGCTTTT TTG-3') or the SENP1 gene (NM_001267595.1; 581-2,515 bp) were subcloned into pCMV-Myc (provided by Professor Huang Jianyong, Peking University, Beijing, China), and were then cloned into a lentiviral vector, pCDH-CMV-MCS-EF1-copGFP (5'-GATCCGAATTGCCACAACAGGGTCGTGTTCAAGAG AATCACATCTTCTTCCTCCATTCTTTTTTG-3'). Untreated cells were considered the control group, and cells transduced with the empty vector were considered the nonsense group. Transduction was performed using RNAifectin reagent (Applied Biological Materials, Inc., Richmond, BC, Canada), according to the manufacturer's protocol. Briefly, once 143B osteosarcoma cells were cultured to $60-70 \%$ confluence, $5 \mu \mathrm{l}$ viral suspension $\left(10^{8}\right.$ titer) was placed on cell monolayers. Flasks were then incubated at $37^{\circ} \mathrm{C}$ and $5 \% \mathrm{CO}_{2}$ for $6 \mathrm{~h}$, after which time the viral suspension was removed and replaced with fresh media. The effect of gene transduction was verified by western blotting.

Immunofluorescence staining. Cells with or without gene transduction were cultured for a further $48 \mathrm{~h}$. Subsequently, the cells were fixed with $4 \%$ paraformaldehyde (Sigma-Aldrich; Merck KGaA), permeabilized in $0.5 \%$ Trixon X-100 in PBS for $5 \mathrm{~min}$, blocked with $3 \%$ bovine serum albumin (cat. no. 9048-46-8; Sigma-Aldrich; Merck KGaA) in PBS for $1 \mathrm{~h}$ at room temperature. Cells were then incubated overnight at $4^{\circ} \mathrm{C}$ with anti-Ki67 antibodies (1:500, cat. no. ab15580; Abcam), followed by further incubation at room temperature for $1 \mathrm{~h}$ with Alexa Fluor ${ }^{\circledR}$ 594-conjugated goat anti-rabbit IgG (1:400; cat. no. ab150080; Abcam) at $2 \mu \mathrm{g} / \mathrm{ml}$. Nuclear DNA was labeled blue with DAPI. Images were captured under a confocal microscope (Carl Zeiss AG, Oberkochen, Germany). Image-Pro Plus 6.0 software (Media Cybernetics, Inc., Rockville, MD, USA) was used for image analysis.

Cell cycle analysis. Cells with or without gene transduction were further cultured for $48 \mathrm{~h}$, after which, they were collected and fixed in $70 \%$ ethanol for $30 \mathrm{~min}$ at $4^{\circ} \mathrm{C}$, and were then treated with the DNA-binding dye propidium iodide $(50 \mu \mathrm{g} / \mathrm{ml})$ and RNase $(1 \mathrm{mg} / \mathrm{ml})$ for $30 \mathrm{~min}$ at $37^{\circ} \mathrm{C}$ in the dark. Finally, red fluorescence was analyzed using a FacsCalibur ${ }^{\mathrm{TM}}$ flow cytometer and CellQuest software version 4.0 (both from BD Biosciences, Franklin Lakes, NJ, USA), according to a standard protocol; a peak fluorescence gate was used to discriminate aggregates.

Apoptosis assay. Cells with or without gene transduction were further cultured for $48 \mathrm{~h}$. Subsequently, apoptosis was analyzed using an Annexin $\mathrm{V}$ fluorescein isothiocyanate apoptosis detection kit (BD Biosciences) and flow cytometry within $1 \mathrm{~h}$, according to the manufacturer's protocol.

Invasion assay. Cell invasion ability was examined using 6-well Transwell chambers and a reconstituted extracellular matrix membrane (BD Biosciences), according to a previously reported method (39). Briefly, cells with or without gene transduction were seeded into the upper chamber at $1 \times 10^{4}$ cells/well; $600 \mu 1$ DMEM supplemented with 10\% FBS was added into the lower chamber. After $48 \mathrm{~h}$, the upper chamber was removed and the membrane was stained with hematoxylin. The number of cells permeating the membrane was quantified under an inverted microscope (Olympus cellSens Entry 1.16; Olympus Corporation).

Lactate dehydrogenase ( $L D H)$ activity detection. Adherent cells with or without SENP1 or HSVtk gene transduction were cultured in DMEM supplemented with 10\% FBS containing $1 \mathrm{mg} / \mathrm{ml} \mathrm{GCV}$ (cat. no. Y0001129; Sigma-Aldrich; Merck KGaA) in 24-well plates. For transduction with the HSVtk gene, 143B osteosarcoma cells at 95\% confluence were incubated with Ad-CMV-tk (provided by Institute of Life Science, Nankai University, Tianjin, China) at a multiplicity of infection of 100 at $37^{\circ} \mathrm{C}$ and $5 \% \mathrm{CO}_{2}$ for $24 \mathrm{~h}$. The transduction efficacy was detected by western blotting, as aforementioned. Anti-TK (1:5,000, cat. no. ab76495) and anti- $\beta$-actin (1:1,000, cat. no. ab8227) (both from Abcam) primary antibodies, and anti-rabbit IgG secondary antibodies $(1: 2,000$, cat. no. sc-516087; Santa Cruz Biotechnology, Inc.) were used in this experiment. Meanwhile, the 143B cells with or without SENP1 or HSVtk gene transduction were cultured in suspension in DMEM/F12 medium containing B27, $20 \mathrm{ng} / \mathrm{ml}$ basic fibroblast growth factor, $20 \mathrm{ng} / \mathrm{ml}$ epidermal growth factor and $1 \mathrm{mg} / \mathrm{ml} \mathrm{GCV}$ in 24-well plates. After $48 \mathrm{~h}$, the conditioned medium was collected, and the LDH content was measured by ELISA using an LDH Activity Assay kit (cat. no. YM-LH0351; Shanghai Yuanmu Biotechnology Co., Ltd., Shanghai, China), according to the manufacturer's protocol. The medium was maintained at room temperature for $5 \mathrm{~min}$, and the optical density (OD) was subsequently recorded using a microplate reader at $450 \mathrm{~nm}$. The activity of LDH was derived from the OD values and expressed as U/l.

Xenograft tumor assay. The animal experiments were approved by the Animal Ethics Committee of Tianjin Fifth Central Hospital (Tianjin, China). A total of 32 female nude mice (age, 4 weeks; weight, 14-16 g) were purchased from the Animal Center of Academy of Military Medical Sciences (Beijing, China) and were housed in the Experimental Animal Center of The Fifth Central Hospital of Tianjin. Mice were maintained under a controlled temperature $\left(22-24^{\circ} \mathrm{C}\right)$ and stable humidity (40-60\%), under a 12-h light/dark cycle with ad libitum access to food, water. The subcutaneous cancer model was established as previously described (40). Briefly, 32 female nude mice (age, 4 weeks) were randomly divided into the following four groups; i) Control group, in which $1 \times 10^{7} 143 \mathrm{~B}$ cells were implanted and, after 15 days, the mice were treated with PBS equivalent to GCV volume; ii) SENP1 group, in which $1 \times 10^{7}$ SENP1/143B cells were implanted and, after 15 days, the 
mice were treated with PBS; iii) HSVtk/GCV group, in which $1 \times 10^{7} \mathrm{HSVtk} / 143 \mathrm{~B}$ cells were implanted and, after 15 days, the mice were treated with GCV at $15 \mathrm{mg} / \mathrm{kg}$ every $48 \mathrm{~h}$ for 15 days; iv) combined group, in which the same number of SENP1/HSVtk/143B cells were implanted and, after 15 days, the mice were treated with GCV at $15 \mathrm{mg} / \mathrm{kg}$ every $48 \mathrm{~h}$ for 15 days. The present study ensured that all subcutaneous tumors were isolated and that no multiple tumors appeared in the same cell inoculation site. Tumor growth was monitored by caliper measurement every 5 days for 30 days. Tumor volume (V) was calculated as follows: $\mathrm{V}=\mathrm{L} \times \mathrm{W}^{2} \times 0.5$; $\mathrm{L}$, length; W, width. On the 30th day after tumor inoculation, the mice were sacrificed. The longest diameter of the subcutaneous tumor was measured, and tumor weight was determined. Subsequently, these subcutaneous tumors were carefully collected, necrotic tissue was removed and the tumors were cut into small blocks $\left(0.5 \times 0.5 \times 0.3 \mathrm{~cm}^{3}\right.$ volume). The tumor blocks were then embedded in paraffin for in situ apoptosis and immunohistochemistry experiments. Cell apoptosis in frozen sections was detected according to the TUNEL method using an in situ cell death kit (Roche Diagnostics), according to the manufacturer' s protocol. SUMO1, SENP1 and PCNA protein expression was detected by immunohistochemistry, using primary antibodies against SUMO1 (1:400, cat. no. ab11672), SENP1 (1:200, cat. no. ab108981) and PCNA (1:10,000, cat. no. ab29) (all from Abcam), as previously described (41). After primary antibody incubation overnight at $4^{\circ} \mathrm{C}$, goat anti-rabbit IgG $\mathrm{H} \& \mathrm{~L}$ horseradish peroxidase-conjugated secondary antibody (1:5,000, cat. no. ab205718) or goat anti-mouse IgG H\&L horseradish peroxidase-conjugated secondary antibody (1:1,000, cat. no. ab6789) (both from Abcam) was applied at $37^{\circ} \mathrm{C}$ for $1 \mathrm{~h}$. All images were captured under a microscope (Olympus BX53; Olympus Corporation).

Statistical analysis. All experiments were repeated at least three times. Data are expressed as the means \pm standard deviation. When the averages of two groups were compared, the results were analyzed by Student's t-test. When averages among three or more groups were compared, the results were analyzed by one-way analysis of variance (ANOVA), and Bonferroni correction was used to control the type I error following one-way ANOVA. All tests were two-tailed, and $\mathrm{P} \leq 0.05$ was considered to indicate a statistically significant difference. GraphPad Prism 6 software (GraphPad Software, Inc., La Jolla, CA, USA) was used for all statistical tests.

\section{Results}

Expression of SENP1 is significantly decreased in osteosarcoma tissues and tumor cell lines. The present study initially examined the expression of SENP1 and SUMO1 in osteosarcoma tissues and adjacent tissues. The expression levels of SENP1 were significantly lower in osteosarcoma tissues compared with in the adjacent tissues; expression levels were $<0.2$-fold those in adjacent tissues. Conversely, the expression levels of SUMO1 in the covalent binding state were significantly higher in osteosarcoma tissues than in adjacent tissues; however, the expression levels of SUMO1 in the free state were comparable in the cancerous and adjacent tissues (Fig. 1A). Similar trends were detected in osteosarcoma cell lines, with the exception of the expression levels of free SUMO1. The expression levels of SUMO1 in the free state were slightly lower in osteosarcoma cell lines than in the osteoblast cell line hFOB1.19 (Fig. 1B). In addition, the expression levels of SENP1 were reduced in osteosarcoma cell lines compared with in hFOB1.19 cells. Conversely, the expression levels of conjugated SUMO1 were increased in osteosarcoma cell lines compared with in hFOB1.19 cells (Fig. 1B).

SENPI and SUMO1 expression patterns are distinctly different between cancer stem cells and non-cancer stem cells. To analyze the expression patterns of SENP1 and SUMO1 in cancer stem cells and non-cancer stem cells, CD133 ${ }^{+}$and CD133- osteosarcoma cells were assessed by flow cytometry. A lower expression of SENP1, and a higher expression of conjugated and free SUMO1 were detected in CD133+ osteosarcoma cells compared with in CD133- cells (Fig. 1C). These findings suggested that a large number of proteins may be covalently bound to SUMO1 in these cancer stem cells.

In theory, chemotherapeutic drugs fail to treat osteosarcoma due to a small percentage of cancer stem cells that persist in a quiescent state $\left(\mathrm{G}_{0}\right)$, allowing them to survive chemotherapeutic drug treatments (42). To better understand the role of SENP1 in the stemness maintenance of osteosarcoma cells, gel stress in combination with stem cell growth factors was used, which limits cancer stem cells in states of quiescence, proliferation or senescence. The results demonstrated that cancer stem cells in the resting state had relatively weaker SENP1 expression and stronger conjugated SUMO1 expression compared with in cells in the proliferating or senescent states (Fig. 1D). These results further suggested that high protein SUMOylation levels may be an important factor for cancer stem cell maintenance.

To confirm this inference, the expression levels of two key stem-maintaining proteins, Oct4 and HIF-1 $\alpha$, and PCNA, an important marker of cell proliferation status, were detected. These proteins have been confirmed as SUMO1 target proteins, which are involved in maintaining stemness of stem cells (43). As expected, in the resting state, osteosarcoma stem cells expressed higher levels of Oct 4 and HIF-1 $\alpha$ but only low level of PCNA expression compared with in cells in the proliferating or senescent states (Fig. 1D).

SUMO1 silencing induces osteosarcoma stem cells to rapidly age, strongly inhibits cell proliferation and migration, and induces cell apoptosis. Since SUMO1 serves an important role in maintaining the stemness of stem cells, the present study detected the effects of SUMO1 gene silencing on osteosarcoma stem cells. Upon silencing the SUMO1 gene by RNA interference in $\mathrm{CD}_{133^{+}}$osteosarcoma cells (Fig. 2A), the cancer stem cells quickly lost their ability to maintain stemness as indicated by the inability to maintain a suspended state of clonal spheres in stem cell maintenance culture medium (Fig. 2B). After the cells in the spheres were mechanically dispersed, the CD133 ${ }^{+}$ population was detected by flow cytometry. The CD133 population was decreased from 5-7 to $0.2-0.5 \%$ (Fig. 2C). In addition, the positive rate of Ki67 decreased from 90-95 to $30-37 \%$ (Fig. 2D). Flow cytometry also detected a large proportion of cancer stem cells that had transitioned from $\mathrm{G}_{0} / \mathrm{G}_{1}$ phase to $\mathrm{S} / \mathrm{G}_{2}$ phase (Fig. $2 \mathrm{E}$ ). These results indicated 
A

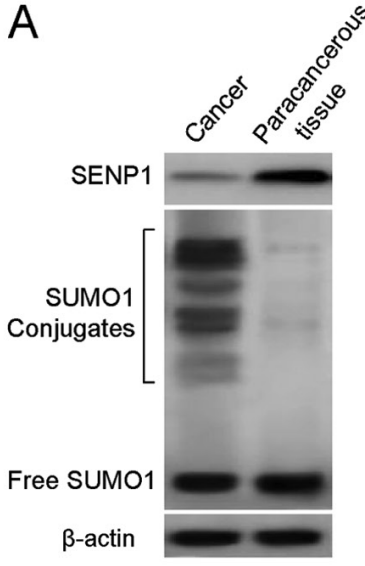

C

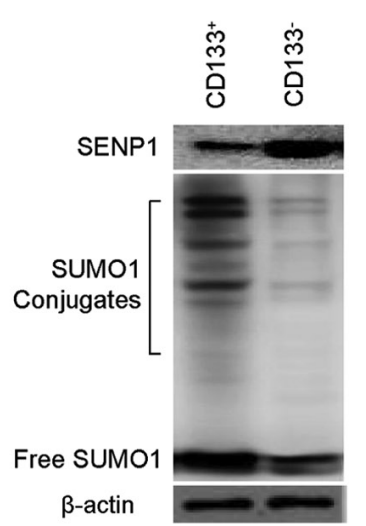

$\mathrm{B}$
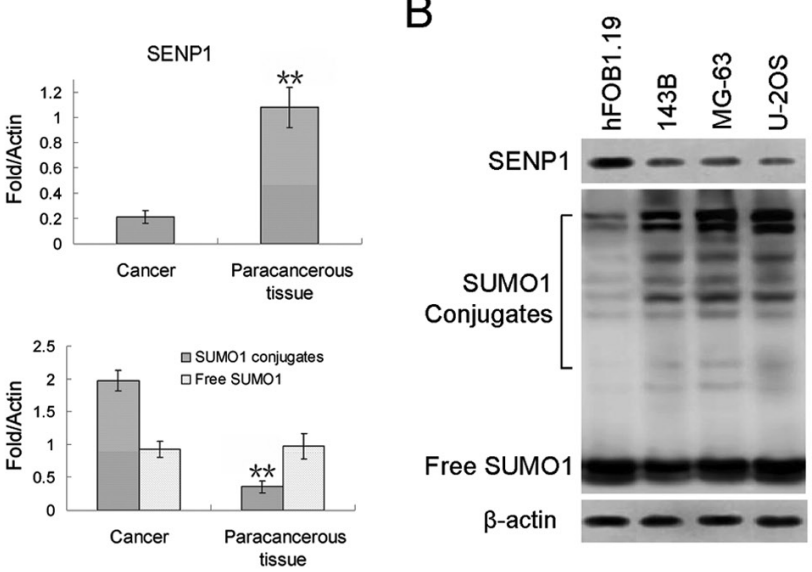
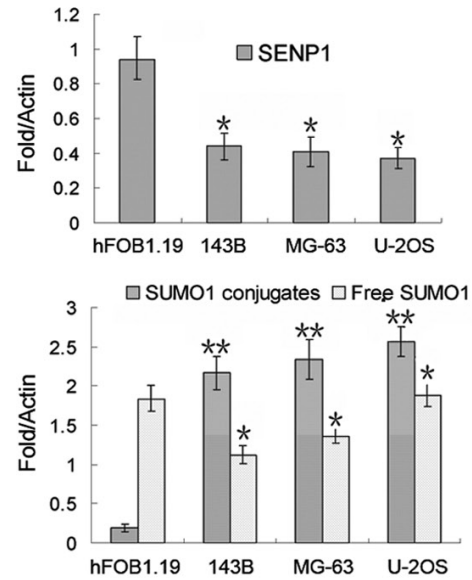

D

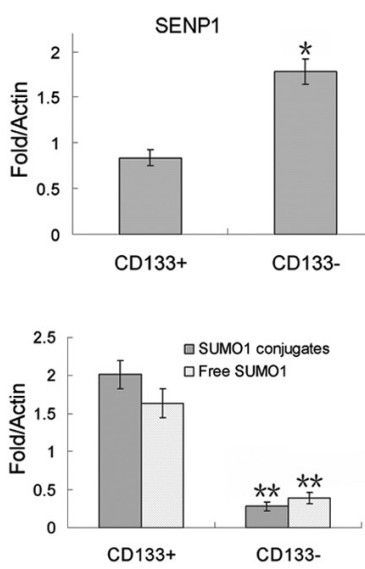

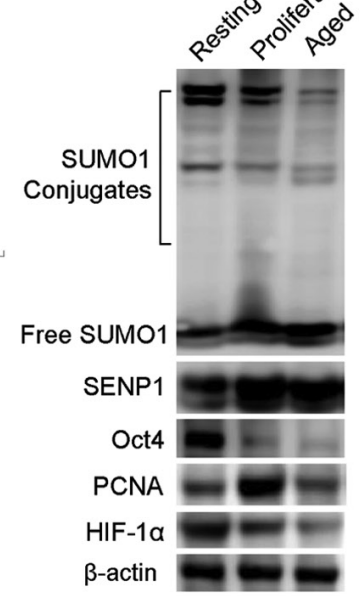
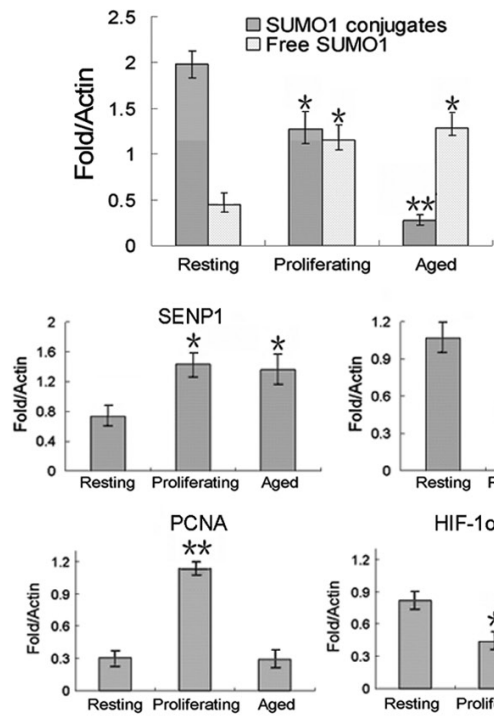

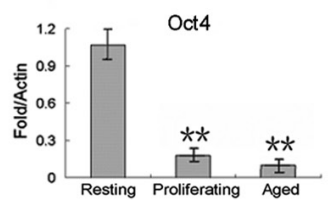

HIF-1 $\alpha$

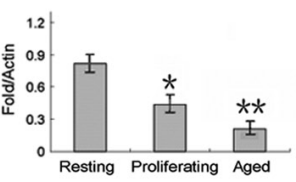

Figure 1. Expression of SENP1 is significantly decreased in osteosarcoma, particularly in osteosarcoma stem cells. (A) Expression of SENP1, conjugated SUMO1 and free SUMO1 in osteosarcoma and adjacent tissues, as detected by western blotting. ${ }^{* *} \mathrm{P}<0.01$ compared with the cancer group. (B) Expression of SENP1, conjugated SUMO1 and free SUMO1 in osteosarcoma cell lines with different differentiation grades, as detected by western blotting. "P $<0.05$ and ${ }^{* *} \mathrm{P}<0.01$ compared with the hFOB1.19 group. (C) Expression of SENP1, conjugated SUMO1 and free SUMO1 in CD133 ${ }^{+}$and CD133- 143B osteosarcoma cells, as detected by western blotting. ${ }^{*} \mathrm{P}<0.05$ and ${ }^{* *} \mathrm{P}<0.01$ compared with the CD133+ group. (D) Expression of SENP1, conjugated SUMO1 and free SUMO1 in CD133 $143 \mathrm{~B}$ osteosarcoma stem cells in various growth states, as detected by western blotting. Graphs represent three independent experiments. ${ }^{*} \mathrm{P}<0.05$ and ${ }^{* *} \mathrm{P}<0.01$ compared with the resting cells group. Data are presented as the means \pm standard deviation. CD133, cluster of differentiation 133 ; HIF-1 $\alpha$, hypoxia-inducible factor $1 \alpha$; PCNA, proliferating cell nuclear antigen; SENP1, SUMO1 specific peptidase 1; SUMO1, small ubiquitin-like modifier 1.

that, upon SUMO1 gene silencing, osteosarcoma stem cells failed to maintain stemness characteristics.

The present study also examined the effects of SUMO1 gene silencing on invasion and apoptosis of osteosarcoma stem cells. The results of transwell assays indicated that knockdown of the SUMO1 gene inhibited the migration of osteosarcoma cells (Fig. 2F). Flow cytometry demonstrated that SUMO1 gene silencing increased the apoptosis of osteosarcoma cells (Fig. 2G). These results revealed that silencing SUMO1 may cause osteosarcoma stem cells to rapidly age, resulting in the cell cycle shifting from $G_{0} / G_{1}$ phase to $S / G_{2}$ phase, decreases in cell proliferation and migration, and an increase in apoptotic rate.

Overexpression of SENP1 decreases stemness maintenance, and slightly affects the migration and apoptosis of osteosarcoma stem cells. Since SUMO1 gene silencing directly led to rapid aging of osteosarcoma stem cells, it was hypothesized that drugs that directly target SUMO1 may exert significant side effects. Therefore, the present study investigated whether overexpression of SENP1, a SUMO1-specific peptidase, released its target proteins from conjugates without affecting the viability of most cells. The results demonstrated that overexpression of SENP1 decreased the maintenance of osteosarcoma stem cell stemness, but only slightly affected cell migration and apoptosis.

The morphology of osteosarcoma stem cells overexpressing the SENP1 gene (Fig. 3B) was different from that of SUMO1 gene-silenced cancer stem cells (Fig. 2B). SENP1-overexpressing cells formed spheres with an obvious necrotic center and visible cell debris when cultured in stem cell-maintaining medium (Fig. 3B). Decreased expression of Ki67 (Fig. 3C) and a shift in the cell cycle from $\mathrm{G}_{0} / \mathrm{G} 1$ to $\mathrm{S} / \mathrm{G}_{2}$ phase (Fig. 3D) confirmed that overexpression of SENP1 induced loss of the stemness maintenance capability in cancer stem cells to a certain extent. However, the results of cell migration and apoptosis 
A

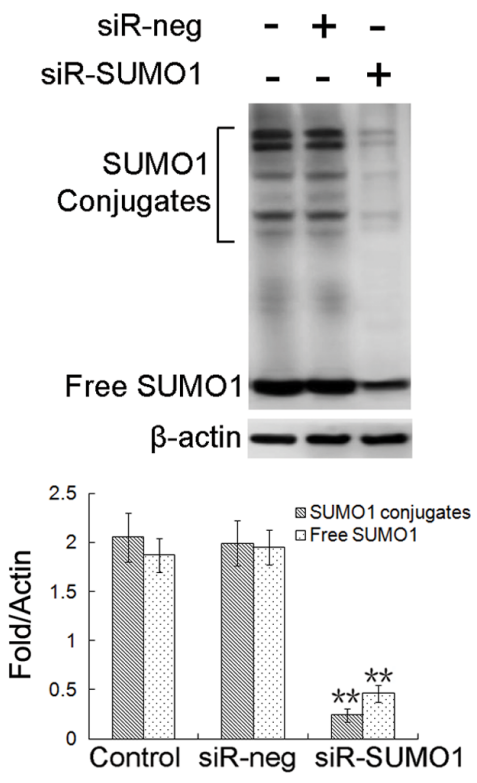

B

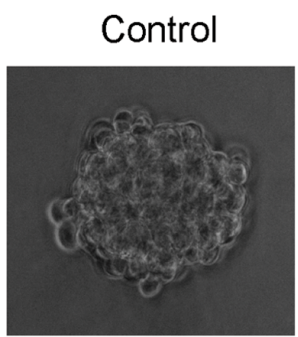

C
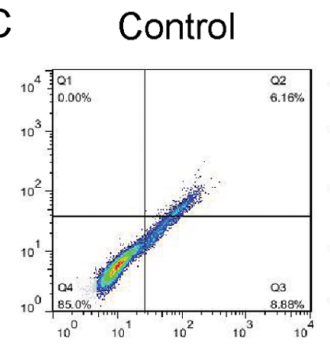

siR-neg

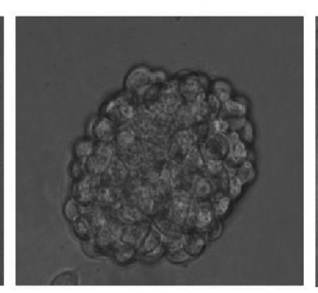

siR-neg
siR-SUMO1

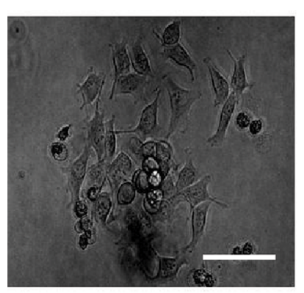

SiR-SUMO1
D Control

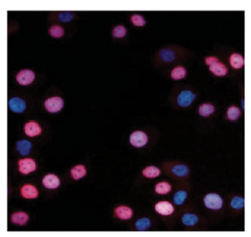

siR-neg

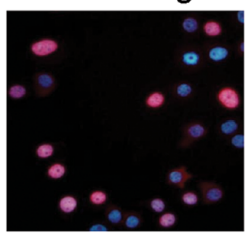

SiR-SUMO1

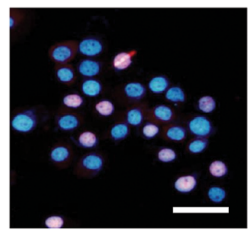

E Control

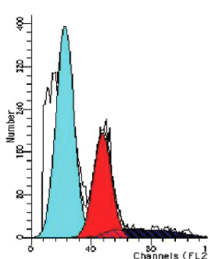

siR-neg

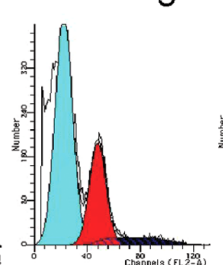

SiR-SUMO1

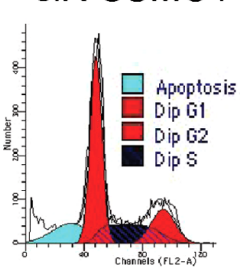

G Control siR-neg

$\mathrm{F}$

Control

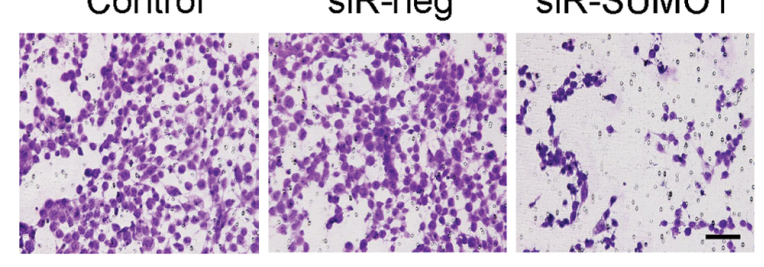

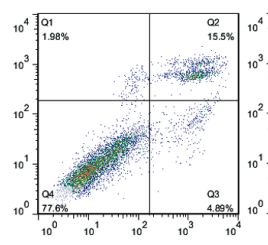

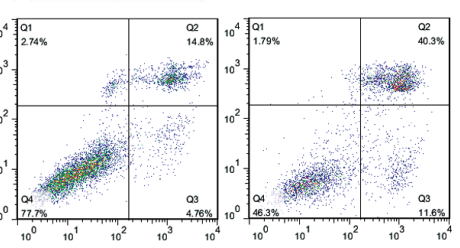

Figure 2. SUMO1 gene silencing induces osteosarcoma stem cells to undergo rapid aging, strongly inhibits cell proliferation and migration, and induces apoptosis. (A) Expression of conjugated and free SUMO1 was detected following SUMO1 gene silencing. (B) Alterations in clonal sphere morphology of osteosarcoma stem cells following SUMO1 gene silencing (scale bar, $50 \mu \mathrm{m}$ ). (C) Proportion of CD133 $143 \mathrm{~B}$ osteosarcoma stem cells, as detected by flow cytometry. (D) Expression of Ki67 was detected by immunocytochemistry following SUMO1 gene silencing in CD133 ${ }^{+} 143 \mathrm{~B}$ osteosarcoma stem cells (red, Ki67; blue, DAPI, all images presented are merged images of Ki67 and DAPI staining; scale bar, $50 \mu \mathrm{m}$ ). (E) Cell cycle alterations were examined by flow cytometry. (F) Alterations in cell migration were detected by transwell assays (scale bar, $50 \mu \mathrm{m}$ ). (G) Cell apoptosis was examined by flow cytometry. CD133, cluster of differentiation 133; neg, negative; siR, small interfering RNA; SUMO1, small ubiquitin-like modifier 1.

assays indicated a small change in cell migration (Fig. 3E) and only a slight increase in apoptosis (Fig. 3F).

To verify these findings, four confirmed target proteins of SUMO1, PCNA, Oct4, HIF-1 $\alpha$ and Akt1, two migration-associated proteins, MMP2 and MMP9, and the proapoptotic protein caspase-3 were detected by western blotting. The results demonstrated that SUMO1 gene silencing significantly decreased the expression of all these detected proteins, with the exception of Akt1 (Fig. 3G). However, compared with the control group, overexpression of SENP1 reduced the expression of PCNA, Oct4, MMP9, HIF-1 $\alpha$ and caspase-3, but had no significant effect on MMP2 and Akt1 (Fig. 3G). One possible explanation is that these three proteins are not direct targets of SUMO1.

Overexpression of SENP1 significantly increases the sensitivity of osteosarcoma stem cells to HSVtk/GCV in vitro. To determine whether SENP1 could reduce the stemness-maintaining ability of osteosarcoma stem cells and increase their sensitivity to chemotherapeutic drugs, a conventional chemotherapeutic drug system, HSVtk/GCV, which has been demonstrated to be effective for most cancers, was applied to the cancer stem cells. The results demonstrated that the tk gene was successfully transduced into the target cells (Fig. 4A), and HSVtk/GCV significantly increased LDH levels in the conditioned medium of adherent cells and the proportion of apoptotic cells. However, it only served a minor role in killing osteosarcoma stem cells, indicating chemotherapeutic resistance of osteosarcoma stem cells to HSVtk/GCV. Conversely, when combined with application of the SENP1 plasmid, the cancer stem cells underwent marked cell apoptosis (Fig. 4B-D). Similar to the results presented in Fig. 3F, SENP1 alone only had a slight effect on apoptosis of adherent cancer cells and suspended cancer stem cells (Fig. 4B-D). These results indicated that overexpression of 


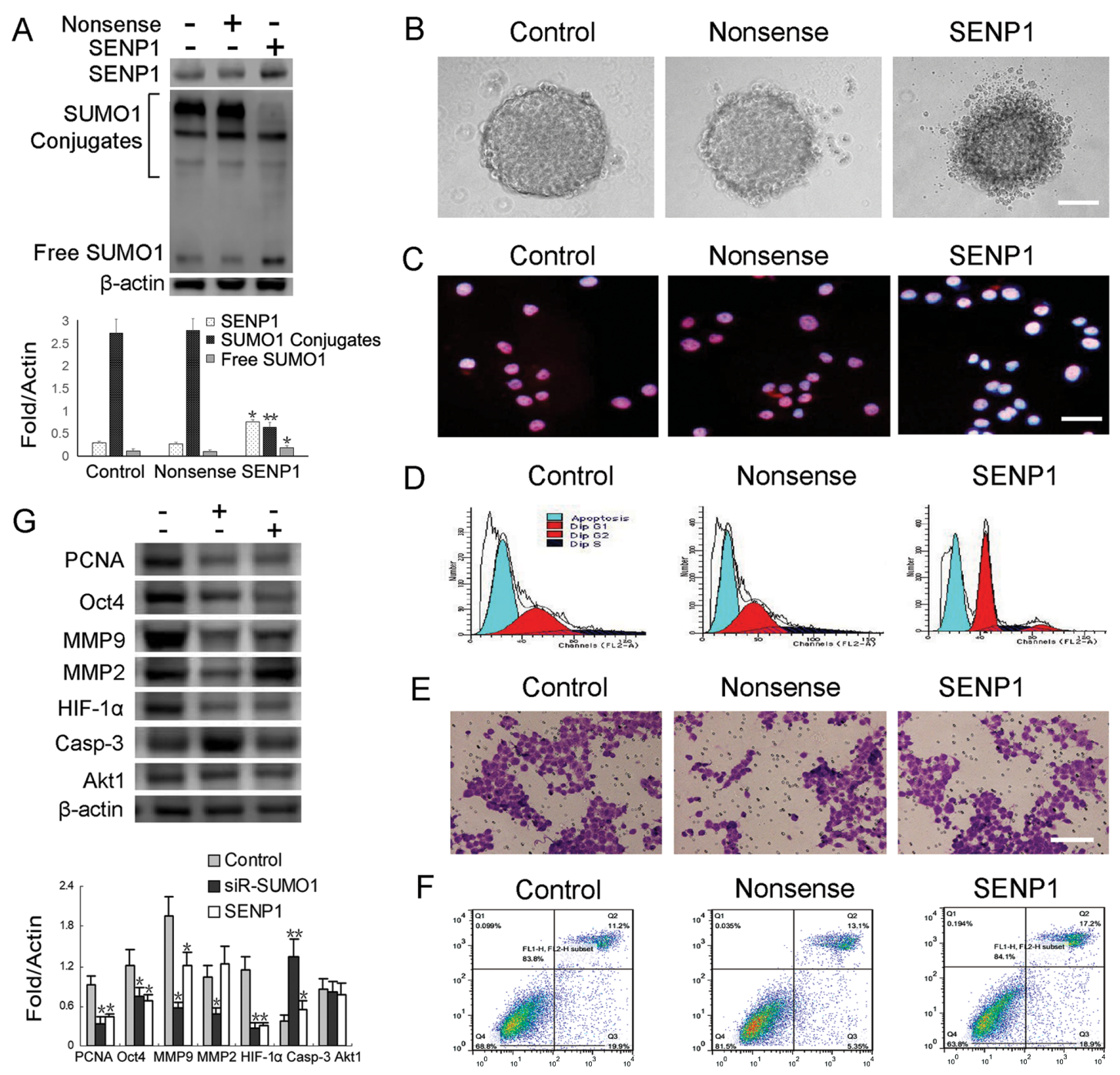

Figure 3. SENP1 overexpression markedly decreases stemness maintenance, but only slightly affects the migration and apoptosis of osteosarcoma stem cells. (A) Expression of SENP1, conjugated SUMO1 and free SUMO1, as detected by western blotting following SENP1 gene transduction. (B) Alterations in clonal sphere morphology of osteosarcoma stem cells following SENP1 gene transduction (scale bar, $50 \mu \mathrm{m}$ ). (C) Expression of Ki67 was detected by immunocytochemistry following transduction of SENP1 in CD133 ${ }^{+}$143B osteosarcoma stem cells (red, Ki67; blue, DAPI, all images presented are merged images of Ki67 and DAPI staining; scale bar, $50 \mu \mathrm{m}$ ). (D) Cell cycle alterations were examined by flow cytometry. (E) Alterations in cell migration were detected by transwell assays (scale bar, $50 \mu \mathrm{m}$ ). (F) Cell apoptosis was examined by flow cytometry. (G) Proteins associated with tumor stemness maintenance (PCNA, Oct4, HIF-1 $\alpha$ and Akt1), tumor cell migration-associated proteins (MMP2 and MMP9) and the apoptosis-related protein caspase-3 were detected by western blotting following SUMO1 gene silencing or SENP1 gene transduction in 143B osteosarcoma stem cells. Akt1, protein kinase B; CD133, cluster of differentiation 133; HIF-1 $\alpha$, hypoxia-inducible factor 1 $\alpha$; MMP, matrix metalloproteinase; PCNA, proliferating cell nuclear antigen; SENP1, SUMO1 specific peptidase 1; siR, small interfering RNA; SUMO1, small ubiquitin-like modifier 1.

SENP1 alone may not cause obvious phenotypic abnormalities of stem cells normally present in the body, which is crucial to reduce the side effects of chemotherapeutic drugs.

SENP1 overexpression significantly increases the sensitivity of osteosarcoma stem cells to HSVtk/GCV in vivo. To verify the therapeutic effects of combined application of the SENP1 plasmid and HSVtk/GCV in vivo, immune-deficient mice were employed in the present study. The results were similar to those obtained in vitro. Overexpression of SENP1 alone did not induce significant tumor growth inhibition (Fig. 5A-D). Treatment with HSVtk/GCV alone inhibited tumor growth and induced apoptosis of tumor cells to a certain extent; however, it could not completely eliminate the tumor (Fig. 5A-D). Combined application of the SENP1 plasmid and HSVtk/GCV further reduced tumor volume and induced apoptosis (Fig. 5E and F). Immunohistochemistry results from tumor tissues revealed that transduction with the of SENP1 gene alone reduced the expression levels of SUMO1 and PCNA. Treatment with HSVtk/GCV alone reduced PCNA protein levels, but had no effect on SUMO1 expression. Furthermore, combination therapy reduced the expression of SUMO1 and PCNA to a greater extent (Fig. 5G). However, even combination therapy could not completely inhibit the growth of osteosarcoma (Fig. 5A-D). Therefore, more potential molecular mechanisms need to be investigated, and more targeted drugs need to be developed and applied.

\section{Discussion}

The present study initially examined the expression levels of SUMO1 in osteosarcoma tissues and adjacent tissues. A high 

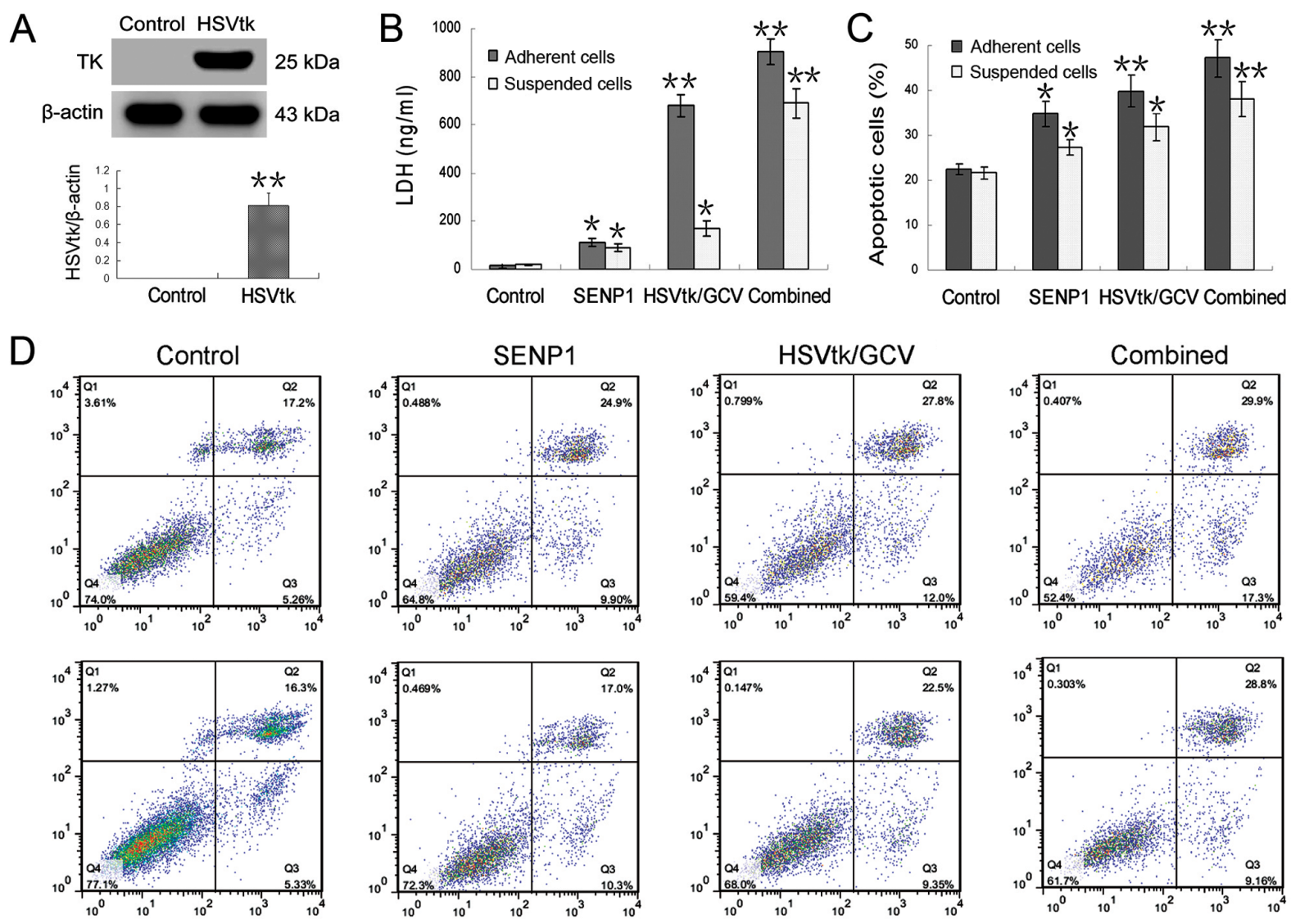

Figure 4. SENP1 overexpression significantly increases the sensitivity of osteosarcoma stem cells to HSVtk/GCV in vitro. (A) HSVtk gene transduction efficiency was detected by western blotting. (B) LDH content was measured using an ELISA after subjecting adherent osteosarcoma cells or suspended osteosarcoma stem cells to various treatments. (C and D) Cell apoptosis was detected by flow cytometry. Graphs represent three independent experiments. Data are presented as the means \pm standard deviation. ${ }^{*} \mathrm{P}<0.05$ and ${ }^{* *} \mathrm{P}<0.01$ compared with the control group. HSVtk/GCV, herpes simplex virus thymidine kinase/ganciclovir; LDH, lactate dehydrogenase; SENP1, SUMO1 specific peptidase 1.

level of conjugated SUMO1 was detected in osteosarcoma tissues; however, the expression levels of conjugated SUMO1 were very low in the adjacent tissues. This observation is consistent with findings in other types of tumor, including breast cancer, glioma and prostate cancer (44). A large number of proteins involved in tumor proliferation, DNA repair, migration, invasion, immune escape and anti-apoptosis are targets of SUMO1 (45).

According to the requirements of tumor growth, SUMO1 can be recruited to form conjugates with its target proteins to stabilize specific protein conformations, assist in completion of nuclear translocation, and activate molecular switches that control diverse cellular functions (22). Thus far, thousands of proteins have been reported to be regulated by SUMO1 (46).

The transcription factor Oct 4 is a master regulator that determines the fate of pluripotent stem cells and cancer stem cells (47). Wei et al (48) revealed that Oct 4 could be modified by SUMO1 in vivo and in vitro. SUMOylation of Oct 4 occurs at a single lysine, Lys118, located at the end of the amino-terminal transactivation domain and next to the Pit1-Oct-Unc86 DNA binding domain. Conjugate modification of Oct4 by SUMO1 leads to significantly increased Oct4 stability and increased DNA binding (48). In the present study, a negative association was detected between low expression of SENP1 and high expression of conjugated SUMO1 in osteosarcoma stem cells, and the expression levels of Oct 4 were negatively associated with SENP1 expression. Upon SUMO1 knockdown or overexpression of SENP1, the expression levels of Oct4 were significantly downregulated, which was accompanied by the transition from $G_{0} / G_{1}$ to $S / G_{2}$ phase in the cell cycle, and a reduction in the stemness maintenance of osteosarcoma stem cells.

Similar trends were reflected in the expression of PCNA, HIF-1 $\alpha$ and MMP9. SUMOylation of PCNA occurs on lysine 164 , and the results of functional studies suggested that PCNA SUMOylation may prevent unwanted and deleterious recombination during DNA replication $(49,50)$. Leach and Michael (51) suggested that PCNA SUMOylation serves as a molecular 'gas pedal' that controls the speed of replisome movement during $\mathrm{S}$ phase. However, even at the same lysine site on PCNA, there may be various forms of post-translational modification $(50,51)$. At present, research regarding PCNA SUMOylation is considered complex. HIF-1 $\alpha$, which is another widely studied SUMO target protein, is closely associated with the chemoresistance of cancer stem cells (52). Due to their high levels of proliferation, cancer cells often encounter local hypoxia. Under such conditions, HIF-1 $\alpha$ can be conjugated with SUMO1 to prevent further hydrolysis, thereby inducing the formation of new blood vessels to overcome the hypoxic microenvironment $(52,53)$. Akt1 is involved in controlling cell survival, proliferation, metabolism and angiogenesis (54). An Akt SUMOylation mutant exhibits reduced activation, and 

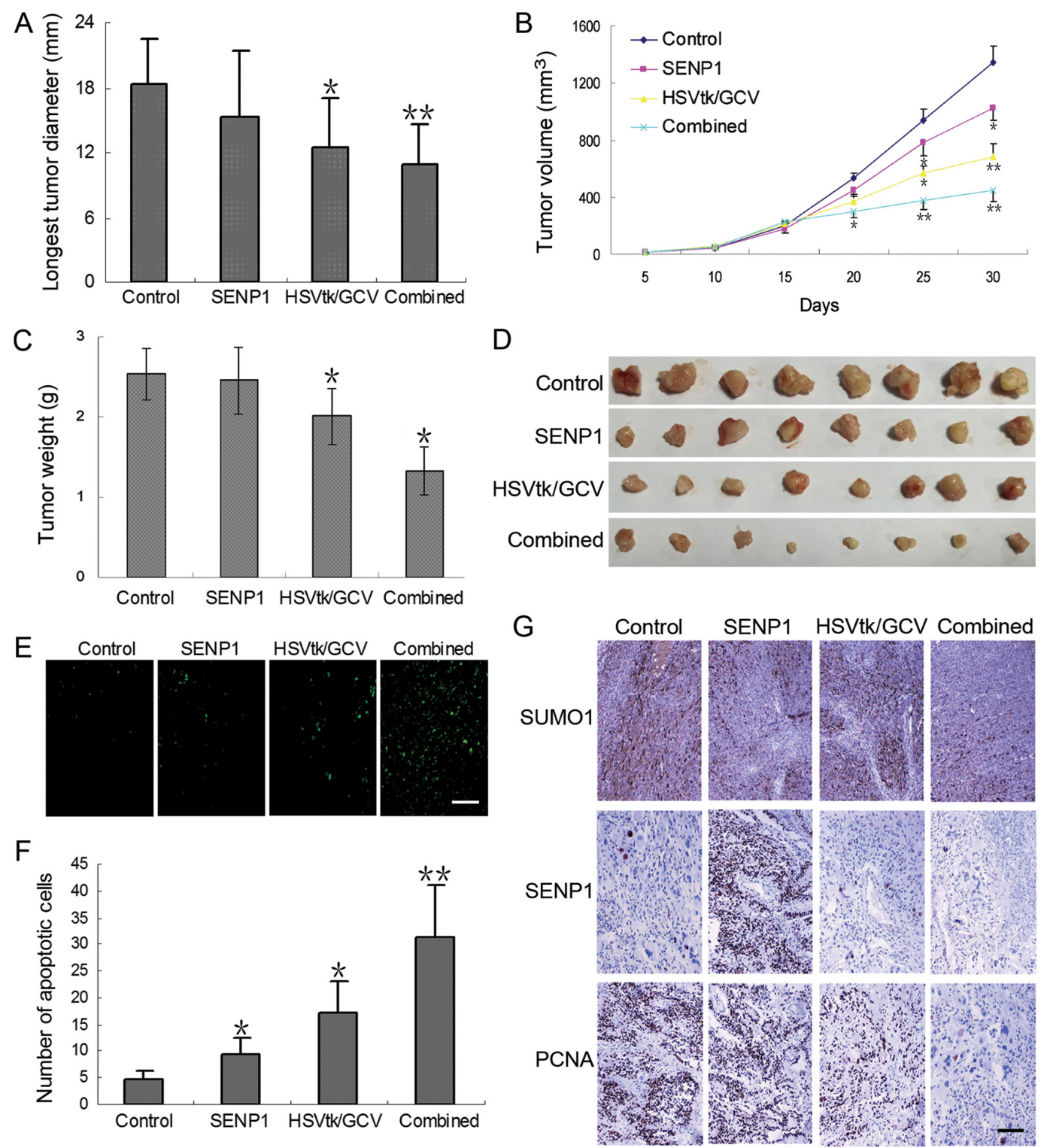

Figure 5. SENP1 overexpression significantly increases the sensitivity of osteosarcoma stem cells to HSVtk/GCV in vivo. (A) Longest tumor diameter was determined at the end of the experiments. (B) Tumor volumes were monitored over 30 days. (C) Tumor weight was determined at the end of the experiments. (D) Tumors were dissected from the subcutaneous region of nude mice. (E and F) Apoptosis in xenografted tumor sections was detected by TUNEL assays (scale bar, $100 \mu \mathrm{m}$ ) and the number of apoptotic cells was quantified. (G) SUMO1, SENP1 and PCNA expression in xenografted tumor sections was detected by immunohistochemistry (scale bar, $25 \mu \mathrm{m}$ ). Graphs represent three independent experiments. Data are presented as the means \pm standard deviation. ${ }^{*} \mathrm{P}<0.05$ and ${ }^{* *} \mathrm{P}<0.01$ compared with the control group. HSVtk/GCV, herpes simplex virus thymidine kinase/ganciclovir; PCNA, proliferating cell nuclear antigen; SENP1, SUMO1 specific peptidase 1; SUMO1, small ubiquitin-like modifier 1.

is associated with decreases in anti-apoptotic and protumor activities compared with the wild-type protein (55). In the present study, upon SUMO1 gene silencing or SENP1 overexpression, a significant downregulation was detected in the expression levels of PCNA, HIF-1 $\alpha$ and MMP9. These results may explain the decline in the stemness-maintaining ability of osteosarcoma stem cells.

The present study aimed to increase the sensitivity of osteosarcoma stem cells to chemotherapeutic drugs using SENP1 to remove conjugated SUMO from stemness-maintaining proteins. Therefore, HSVtk/GCV was used because it is among the most efficient drug systems that cause cell death to rapidly dividing cells. As expected, upon overexpression of SENP1, the expression levels of conjugated SUMO1 were significantly decreased, which was accompanied by a transition from $\mathrm{G}_{0} / \mathrm{G}_{1}$ to $S / G_{2}$ phase. The results of in vitro and in vivo experiments indicated that overexpression of SENP1 significantly enhanced the sensitivity of osteosarcoma stem cells to HSVtk/GCV.

The present study also aimed to reduce the side effects of chemotherapeutic drugs. The results demonstrated that SUMO1 gene silencing by RNA interference induced inhibition of cancer cells, and caused cancer cell death. However, although overexpression of SENP1 induced the transition from $\mathrm{G}_{0} / \mathrm{G}_{1}$ to $\mathrm{S} / \mathrm{G}_{2}$ phase, the effects on cell apoptosis and migration were small. Liu et al recently reported that SUMO silencing can lead to growth arrest and rapid aging of bone marrow mesenchymal stem cells (56). Notably, SUMO silencing may induce marked side effects on normal stem cells, whereas SENP1 overexpression-induced deSUMOylation may significantly reduce the degree of side effects. 
A previous study indicated that Connexin 43 (Cx43), which is a protein involved in gap junctional intercellular communication, can be covalently modified and regulated by SUMO1 in liver cancer stem cells (57). In addition, Cx43 SUMOylation can improve gap junction functions and enhance cell sensitivity to $\mathrm{HSVtk} / \mathrm{GCV}$ (56). It seems contradictory that increasing protein SUMOylation levels in liver cancer stem cells and inducing deSUMOylation in osteosarcoma stem cells can both increase chemosensitivity. Therefore, further studies are required that focus on the complex network of proteins associated with chemosensitivity in these cells.

In conclusion, the present study developed a method that is able to remove conjugated SUMO from target proteins, particularly those that maintain stemness of osteosarcoma stem cells. This strategy may be applied to the clinic in the future to increase the effects of chemotherapeutic drugs while minimizing their side effects.

\section{Acknowledgements}

The authors would like to thank Dr Baojiang Li and Dr Zhongmin Jiang (Department of Pathology, Tianjin Fifth Central Hospital, Tianjin, China) for their help with pathological diagnosis.

\section{Funding}

The present study was supported by the National Natural Science Foundation of China (grant nos. 31671246, 81471175 and 81501073), the Tanggu District Science and Technology Project (grant no. 2013KJXQ03), and the Tianjin Health Bureau Science and Technology Projects (grant nos. 2014KY23 and 2015KZ018).

\section{Availability of data and materials}

The datasets used and/or analyzed during the present study are available from the corresponding author on reasonable request.

\section{Authors' contributions}

GW and DZ designed the experiments. FL, LL, YL, XM and XB performed the experiments and collected data. FL, LL and XL analyzed and interpreted the data. FL and XL drafted the manuscript. FL, XL, GW and DZ revised the paper critically for important intellectual content. GW and DZ agreed to be accountable for all aspects of the work in ensuring that questions related to the accuracy or integrity of any part of the work are appropriately investigated and resolved. All authors read and gave final approval of the version to be published.

\section{Ethics approval and consent to participate}

The present study was approved by the Ethics Committee of Tianjin Medical University Cancer Institute and Hospital (Tianjin, China). The animal experiments were approved by the Animal Ethics Committee of Tianjin Fifth Central Hospital (Tianjin, China).

\section{Patient consent for publication}

Written informed consent was obtained from all patients.

\section{Competing interests}

The authors declare that they have no competing interests.

\section{References}

1. Adamopoulos C, Gargalionis AN,Piperi C and Papavassiliou AG: Recent advances in mechanobiology of osteosarcoma. J Cell Biochem 118: 232-236, 2017.

2. Abarrategi A, Tornin J, Martinez-Cruzado L, Hamilton A, Martinez-Campos E, Rodrigo JP, González MV, Baldini N, Garcia-Castro J and Rodriguez R: Osteosarcoma: Cells-of-origin, cancer stem cells, and targeted therapies. Stem Cells Int 2016: $3631764,2016$.

3. Abed R and Grimer R: Surgical modalities in the treatment of bone sarcoma in children. Cancer Treat Rev 36: 342-347, 2010.

4. Andreou D, Hardes J, Gosheger G, Henrichs MP, Nottrott M and Streitbürger A: Interdisciplinary diagnostic and treatment of bone sarcomas of the extremities and trunk. Handchir Mikrochir Plast Chir 47: 90-99, 2015 (In German).

5. Claude L, Rousmans S, Carrie C, Breteau N, Dijoud F, Gentet JC, Giammarile F, Jouve JL, Kind M, Marec-Bérard P, et al; Fédération nationale des centres de lutte contre le cancer (FNCLCC); Fédération hospitalière de France (FHF); Fédération nationale de cancérologie des CHRU (FNCCHRU); Fédération française de cancérologie des CHG (FFCCHG); centres régionaux de lutte contre le cancer (CRLCC); Société française de lutte contre les cancers de l' enfant et de l' adolescent (SFCE): Standards and Options for the use of radiation therapy in the management of patients with osteosarcoma. Update 2004. Cancer Radiother 9: 104-121, 2005 (In French).

6. Liebner DA: The indications and efficacy of conventional chemotherapy in primary and recurrent sarcoma. J Surg Oncol 111: 622-631, 2015.

7. Biazzo A and De Paolis M: Multidisciplinary approach to osteosarcoma. Acta Orthop Belg 82: 690-698, 2016.

8. Yan GN, Lv YF and Guo QN: Advances in osteosarcoma stem cell research and opportunities for novel therapeutic targets. Cancer Lett 370: 268-274, 2016.

9. Zeng W, Wan R, Zheng Y, Singh SR and Wei Y: Hypoxia, stem cells and bone tumor. Cancer Lett 313: 129-136, 2011.

10. Gibbs CP Jr, Levings PP and Ghivizzani SC: Evidence for the osteosarcoma stem cell. Curr Orthop Pract 22: 322-326, 2011.

11. Brown HK, Tellez-Gabriel M and Heymann D: Cancer stem cells in osteosarcoma. Cancer Lett 386: 189-195, 2017.

12. Seeliger C, Balmayor ER and van Griensven M: miRNAs related to skeletal diseases. Stem Cells Dev 25: 1261-1281, 2016.

13. Bishop MW, Janeway KA and Gorlick R: Future directions in the treatment of osteosarcoma. Curr Opin Pediatr 28: 26-33, 2016.

14. Shang D, Wu J, Guo L, Xu Y, Liu L and Lu J: Metformin increases sensitivity of osteosarcoma stem cells to cisplatin by inhibiting expression of PKM2. Int J Oncol 50: 1848-1856, 2017.

15. Mongre RK, Sodhi SS, Ghosh M, Kim JH, Kim N, Park YH, Kim SJ, Heo YJ, Sharma N and Jeong DK: The novel inhibitor BRM270 downregulates tumorigenesis by suppression of NF- $\mathrm{KB}$ signaling cascade in MDR-induced stem like cancer-initiating cells. Int J Oncol 46: 2573-2585, 2015.

16. Lee OK, Coathup MJ, Goodship AE and Blunn GW: Use of mesenchymal stem cells to facilitate bone regeneration in normal and chemotherapy-treated rats. Tissue Eng 11: 1727-1735, 2005.

17. Bayat M, Virdi A, Rezaei F and Chien S: Comparison of the in vitro effects of low-level laser therapy and low-intensity pulsed ultrasound therapy on bony cells and stem cells. Prog Biophys Mol Biol 133: 36-48, 2018.

18. Liu B, Ma W, Jha RK and Gurung K: Cancer stem cells in osteosarcoma: Recent progress and perspective. Acta Oncol 50: 1142-1150, 2011.

19. Chen JN, Wu DW, Li T, Yang KJ, Cheng L, Zhou ZP, Pu SM and Lin WH: Arylurea Derivatives: A Class of Potential Cancer Targeting Agents. Curr Top Med Chem 17: 3099-3130, 2017.

20. Gong L, Qi R and Li DW: Sumoylation pathway as potential therapeutic targets in cancer. Curr Mol Med 16: 900-905, 2017.

21. Cheng CT, Kuo CY and Ann DK: KAPtain in charge of multiple missions: Emerging roles of KAP1. World J Biol Chem 5: 308-320, 2014.

22. Yang XJ and Chiang CM: Sumoylation in gene regulation, human disease, and therapeutic action. F1000Prime Rep 5: 45, 2013. 
23. Hannoun Z, Greenhough S, Jaffray E, Hay RT and Hay DC: Post-translational modification by SUMO. Toxicology 278: 288-293, 2010

24. Wang $\mathbf{J}$ and Schwartz RJ: Sumoylation and regulation of cardiac gene expression. Circ Res 107: 19-29, 2010

25. Butler JT, Hall LL, Smith KP and Lawrence JB: Changing nuclear landscape and unique PML structures during early epigenetic transitions of human embryonic stem cells. J Cell Biochem 107: 609-621, 2009.

26. Zhu C, Chen C, Huang J, Zhang H, Zhao X, Deng R, Dou J, Jin H, Chen R, Xu M, et al: SUMOylation at K707 of DGCR8 controls direct function of primary microRNA. Nucleic Acids Res 43: 7945-7960, 2015.

27. Jones MC, Fusi L, Higham JH, Abdel-Hafiz H, Horwitz KB, Lam EW and Brosens JJ: Regulation of the SUMO pathway sensitizes differentiating human endometrial stromal cells to progesterone. Proc Natl Acad Sci USA 103: 16272-16277, 2006.

28. Cheng JK: SUMO-specific protease 1 and cancer. Ai Zheng 27 771-774, 2008 (In Chinese).

29. Fasci D, Anania VG, Lill JR and Salvesen GS: SUMO deconjugation is required for arsenic-triggered ubiquitylation of PML. Sci Signal 8: ra56, 2015.

30. Fillat C, Carrió M, Cascante A and Sangro B: Suicide gene therapy mediated by the Herpes Simplex virus thymidine kinase gene/Ganciclovir system: Fifteen years of application. Curr Gene Ther 3: 13-26, 2003

31. Grignet-Debrus C, Noël A, Foidart JM and Calberg-Bacq CM: Identification of factors important for the success of suicide gene therapy after a comparative study of Varicella zoster and Herpes simplex viral thymidine kinases efficacy on breast cancer cells. Cell Mol Biol (Noisy-le-grand) 51: 37-48, 2005.

32. Marples B, Greco O, Joiner MC and Scott SD: Molecular approaches to chemo-radiotherapy. Eur J Cancer 38: 231-239, 2002.

33. Shibata MA, Morimoto J, Ito Y, Kusakabe K and Otsuki Y: Experimental gene therapy in mammary and urinary bladder cancer using electrogene transfer. Med Electron Microsc 37: 216-224, 2004

34. Smythe WR: Prodrug/drug sensitivity gene therapy: Current status. Curr Oncol Rep 2: 17-22, 2000.

35. Ghanbari M, Saberfar E, Goodarzi Z, Lashini H, Ghanbari S, Karamimanesh M and Baesi K: Regulation of HSVtk gene by endogenous microRNA-122a in liver cell lines as suicide gene therapy. Gastroenterol Hepatol Bed Bench 10: 202-207, 2017.

36. Cerella C, Grandjenette C, Dicato M and Diederich M: Roles of apoptosis and cellular senescence in cancer and aging. Curr Drug Targets 17: 405-415, 2016.

37. Liu Z, Jiang Z, Huang J, Huang S, Li Y, Sheng F, Yu S, Yu S and Liu X: Mesenchymal stem cells show little tropism for the resting and differentiated cancer stem cell-like glioma cells. Int J Oncol 44: 1223-1232, 2014

38. Wang J, Liu X, Jiang Z, Li L, Cui Z, Gao Y, Kong D and Liu X: A novel method to limit breast cancer stem cells in states of quiescence, proliferation or differentiation: Use of gel stress in combination with stem cell growth factors. Oncol Lett 12: 1355-1360, 2016.

39. Liu Z, Jiang Z, Huang J, Huang S, Li Y, Yu S, Yu S and Liu X: miR-7 inhibits glioblastoma growth by simultaneously interfering with the PI3K/ATK and Raf/MEK/ERK pathways. Int J Oncol 44: 1571-1580, 2014

40. Liu X, Li G, Su Z, Jiang Z, Chen L, Wang J, Yu S and Liu Z: Poly(amido amine) is an ideal carrier of miR-7 for enhancing gene silencing effects on the EGFR pathway in U251 glioma cells. Oncol Rep 29: 1387-1394, 2013.
41. Li G, Liu X, Liu Z and Su Z: Interactions of connexin 43 and aquaporin-4 in the formation of glioma-induced brain edema. Mol Med Rep 11: 1188-1194, 2015.

42. Orsi GA, Naughtin M and Almouzni G: The epigenome and cancer stem cell fate: Connected by a linker histone variant. Cell Stem Cell 19: 567-568, 2016.

43. Cui CP, Wong CC, Kai AK, Ho DW, Lau EY, Tsui YM, Chan LK, Cheung TT, Chok KS, Chan ACY, et al: SENP1 promotes hypoxia-induced cancer stemness by HIF-1 $\alpha$ deSUMOylation and SENP1/HIF-1 $\alpha$ positive feedback loop. Gut 66: 2149-2159, 2017.

44. Mattoscio D and Chiocca S: SUMO pathway components as possible cancer biomarkers. Future Oncol 11: 1599-1610, 2015.

45. Nuro-Gyina PK and Parvin JD: Roles for SUMO in pre-mRNA processing. Wiley Interdiscip Rev RNA 7: 105-112, 2016.

46. Yang $\mathrm{W}$ and Paschen $\mathrm{W}$ : SUMO proteomics to decipher the SUMO-modified proteome regulated by various diseases. Proteomics 15: 1181-1191, 2015.

47. Villodre ES, Kipper FC, Pereira MB and Lenz G: Roles of OCT4 in tumorigenesis, cancer therapy resistance and prognosis. Cancer Treat Rev 51: 1-9, 2016.

48. Wei F, Schöler HR and Atchison ML: Sumoylation of Oct4 enhances its stability, DNA binding, and transactivation. J Biol Chem 282: 21551-21560, 2007.

49. Tsutakawa SE, Yan C, Xu X, Zhuang Z, Todd Washington M, Tainer JA and Ivanov I: 112 Structurally distinct ubiquitin- and SUMO-modified PCNA: Implications for their distinct roles in the DNA damage response. J Biomol Struct Dyn 1: 70-71, 2015.

50. Burkovics P, Sebesta M, Sisakova A, Plault N, Szukacsov V, Robert T, Pinter L, Marini V, Kolesar P, Haracska L, et al: Srs2 mediates PCNA-SUMO-dependent inhibition of DNA repair synthesis. EMBO J 32: 742-755, 2013.

51. Leach CA and Michael WM: Ubiquitin/SUMO modification of PCNA promotes replication fork progression in Xenopus laevis egg extracts. J Cell Biol 171: 947-954, 2005.

52. Han X, Wang XL, Li Q, Dong XX, Zhang JS and Yan QC: HIF-1 $\alpha$ SUMOylation affects the stability and transcriptional activity of HIF-1 $\alpha$ in human lens epithelial cells. Graefes Arch Clin Exp Ophthalmol 253: 1279-1290, 2015.

53. Gu J, Fan Y, Liu X, Zhou L, Cheng J, Cai R and Xue S: SENP1 protects against myocardial ischaemia/reperfusion injury via a HIF1 $\alpha$-dependent pathway. Cardiovasc Res 104: 83-92, 2014.

54. de la Cruz-Herrera CF, Campagna M, Lang V, del Carmen González-Santamaría J, Marcos-Villar L, Rodríguez MS, Vidal A, Collado M and Rivas C: SUMOylation regulates AKT1 activity. Oncogene 34: 1442-1450, 2015.

55. Li R, Wei J, Jiang C, Liu D, Deng L, Zhang K and Wang P: Akt SUMOylation regulates cell proliferation and tumorigenesis. Cancer Res 73: 5742-5753, 2013.

56. Liu X, Ren W, Jiang Z, Su Z, Ma X, Li Y, Jiang R, Zhang J and Yang X: Hypothermia inhibits the proliferation of bone marrow-derived mesenchymal stem cells and increases tolerance to hypoxia by enhancing SUMOylation. Int J Mol Med 40: 1631-1638, 2017.

57. Shen Y, Li Y, Ma X, Wan Q, Jiang Z, Liu Y, Zhang D, Liu X and Wu W: Connexin 43 SUMOylation improves gap junction functions between liver cancer stem cells and enhances their sensitivity to HSVtk/GCV. Int J Oncol 52: 872-880, 2018.

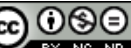

This work is licensed under a Creative Commons Attribution-NonCommercial-NoDerivatives 4.0 International (CC BY-NC-ND 4.0) License. 